\title{
Experimental evaluation of new organic compounds as corrosion inhibitors for mild steel in hydrochloric acid
}

\author{
M.A. Almomani, ${ }^{1}(1) *$ M. Al-Noaimi, ${ }^{2}$ (i) M.T. Hayajneh, ${ }^{1}$ (i) \\ H.H. AlShurafat ${ }^{1}$ and E.M. AlShamaileh ${ }^{3}$ (I)
}

${ }^{1}$ Industrial Engineering Department, Faculty of Engineering, Jordan University of Science and Technology, P.O. Box 3030, Irbid, 22110, Jordan

${ }^{2}$ Chemistry Department, Faculty of Science, Hashemite University, Zarqa, 13133, Jordan

${ }^{3}$ Department of Chemistry, Faculty of Science, University of Jordan, Amman, 11942, Jordan

*E-mail: maalmomani7@just.edu.jo

\begin{abstract}
Mild steel is one of the most widely used construction materials that finds various applications in industry owing to its exceptional mechanical properties and low cost. However, hydrochloric acid is widely used as an efficient pickling agent in steel industries to remove rust and scales, but it accelerates steels corrosion rate. Corrosion inhibitors are one of the most effective methods used to reduce mild steel corrosion in acidic media. In this study, new synthetics organic compounds L1, L2 and L3 were examined as corrosion inhibitors for mild steel in $1 \mathrm{M}$ hydrochloric acid solutions using potentiodynamic polarization, electrochemical impedance spectroscopy (EIS) and scanning electron microscopy (SEM). For the examined concentrations range, it was observed that the inhibition efficiency increased with increasing L1 and L2 concentrations and decreased with increasing L3 concentration. The maximum efficiency of $69 \%$ was achieved at $300 \mathrm{ppm}$ of L2 at room temperature. Based on polarization studies, all the compounds were found to behave as anodic type inhibitors. SEM micrographs showed that the used inhibitors slowed down the corrosion of the surface with fewer cracks and pits observed. The quantum chemical parameters were calculated and showed a good agreement with the experimental results.
\end{abstract}

Keywords: corrosion inhibitors, electrochemical impedance spectroscopy, mild steel, $\mathrm{HCl}$, scanning electron microscope, quantum chemistry calculations.

Received: July 19, 2021. Published: August 19, 2021

doi: $\underline{10.17675 / 2305-6894-2021-10-3-18}$

\section{Introduction}

Mild steel is one of the most preferred commonly used construction materials in various chemical and electrochemical industries, due to its exceptional mechanical proprieties, its environmental stability and because it is economically accepted material [1,2]. Hydrochloric acid is widely used as an efficient pickling agent in steel industries in general to remove the rust and scales. It is highly aggressive and can accelerate corrosion rate of mild steel. Therefore, it is highly important to protect steel against corrosion in $\mathrm{HCl}$ solution [2-5]. 
Corrosion inhibitors is one of the most effective methods for combating corrosion $[6,7]$, and they are commonly used to reduce the corrosion rate of mild steel in acidic media $[5,6,8,9]$. They inhibit corrosion in several ways: as (a) adsorption on the surface of the metal and forming a protective thin film $[6,8,9]$; (b) formation of oxide films on the base metal which reduces the oxygen transfer rate to the metal surface $[9,10]$, and (c) reacting with a corrosive component present in the aqueous media [9]. Organic compounds which contain heteroatoms (such as oxygen, sulfur, nitrogen etc.), aromatic rings and $\pi$ bonds are excellent inhibitors due to their ability to be absorbed on a metal surface [11]. The adsorption depends on the charge of the metal, the structure of the inhibitor molecules [12], and the presence of $\pi$-acceptor groups such as $(-\mathrm{N}=\mathrm{N}-,-\mathrm{C}=\mathrm{O},-\mathrm{C}=\mathrm{N}-$, or $-\mathrm{N}=\mathrm{N}-\mathrm{C}=\mathrm{N}-)$ [5].

Compounds that have azoimine functionality were found to be good inhibitors for steel due to the $\mathrm{Fe}(\mathrm{d} \pi)-\pi^{*}(-\mathrm{N}=\mathrm{N}-\mathrm{C}=\mathrm{N}-)$ bond formation. Many researchers reported that azoimines are good inhibitors for mild steel in hydrochloric acid solution. The effect of the concentrations $\left(0.5-7.5 \cdot 10^{-6} \mathrm{M}\right)$ and the effect of the substituent $\mathrm{Y}$ in $\mathrm{PhN}=\mathrm{N}-\mathrm{C}\left(\mathrm{COCH}_{3}\right)=\mathrm{NC}_{6} \mathrm{H}_{4} \mathrm{Y}$ (where $\left.\mathrm{Y}=\mathrm{OCH}_{3}, \mathrm{CH}_{3}, \mathrm{H}, \mathrm{Br}, \mathrm{Cl}\right)$ on the inhibition of the mild steel were studied at room temperature in $1 \mathrm{M} \mathrm{HCl}$ [5]. The influence of hydrodynamic conditions $(0-2000 \mathrm{rpm})$ at the same temperature range $\left(25-55^{\circ} \mathrm{C}\right)$ and same inhibitors concentrations was studied [13]. Also, the effect of temperature in the range of $\left(25-55^{\circ} \mathrm{C}\right)$ when $\mathrm{Y}=\mathrm{NO}_{2}$ on the inhibition of mild steel in $1 \mathrm{M} \mathrm{HCl}$ was studied [14].

In this study, we investigate the effect of the substituent $\mathrm{X}$ of newly synthesized azoimine compounds L1, L2 and L3 (Figure 1) $\left(\mathrm{H}_{2} \mathrm{~L}=2-\mathrm{PhS}\left(\mathrm{C}_{6} \mathrm{H}_{4}\right) \mathrm{NH}-\mathrm{NC}=\left(\mathrm{COCH}_{3}\right)-\right.$ $\mathrm{NHC}_{6} \mathrm{H}_{4} \mathrm{X}$ ) as corrosion inhibitors on the corrosion rate of mild steel in $1 \mathrm{M}$ hydrochloric acid electrolyte using potentiodynamic polarization, electrochemical impedance spectroscopy (EIS), quantum chemical calculation method and SEM technique. The new ligands are expected to inhibit the steel corrosion by the strong adsorption through the $\mathrm{S}$, the azoimine $(-\mathrm{N}=\mathrm{N}-\mathrm{C}=\mathrm{N}-)$, and $\mathrm{C}=\mathrm{O}$ moieties.

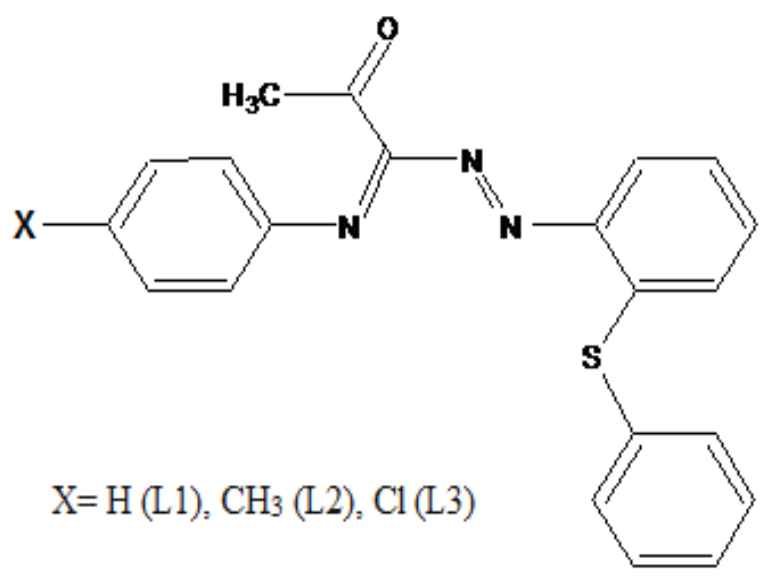

Figure 1. The chemical structure of the investigated azoimine compounds L1, L2 and L3. 


\section{Experimental}

\subsection{Corrosion inhibitors (L1-L3)}

\subsubsection{Materials}

3-Chloro-pentane-2,4-dione, pyridine, sodium nitrite, 2-(phenylthio)aniline, 4chloroaniline, 4-methylaniline and trimethylamine were purchased from Aldrich and used as received without further purification.

\subsubsection{Synthesis}

The ligands (L1-L2) were prepared and characterized according to the published method [15]. The inhibitor L3 was prepared according to the procedure described in reference [15] and the physical characterization is described as follows:

(1Z)- $N$-(4-chlorophenyl)-2-oxo- $\mathrm{N}^{\prime}$-[2(phenylthio)phenyl]propanehydrazonamide (L3).

Yield (3.3 g, 91\%). Anal. Calc. for $\mathrm{C}_{21} \mathrm{H}_{19} \mathrm{~N}_{3} \mathrm{OS}$ : C, 69.78; H, 5.30; N, 11.63; S, 8.87. Found: C, 70.16; H, 5.23; N, 11.65; S, 8.64\%. m.p. $118-120^{\circ} \mathrm{C}$. IR data $(\mathrm{KBr} \operatorname{disc})\left(\mathrm{cm}^{-1}\right)$ : $v(\mathrm{C}=\mathrm{N}) 1575, v(\mathrm{C}=\mathrm{O}) 1675, v(\mathrm{~N}-\mathrm{H}) 3308, v(\mathrm{~N}-\mathrm{H}) 3259 .{ }^{1} \mathrm{H}$ NMR (in $\mathrm{CDC}_{13}, \delta$ ppm): 8.26 $(1 \mathrm{H}, s, \mathrm{NH}), 7.71(1 \mathrm{H}, d, \mathrm{H} 1), 7.48(1 \mathrm{H}, s, \mathrm{NH}), 7.46(2 \mathrm{H}, m, \mathrm{H} 4, \mathrm{H} 3), 7.1(2 \mathrm{H}, t, \mathrm{H} 6), 7.1$ $(3 \mathrm{H}, m, \mathrm{Ph}), 6.98(1 \mathrm{H}, t, \mathrm{X}=\mathrm{H}), 6.87(1 \mathrm{H}, d, \mathrm{H} 2), 6.75(2 \mathrm{H}, d, \mathrm{H} 5), 6.60(2 \mathrm{H}, d, \mathrm{Ph}), 2.85$ $\left(3 \mathrm{H}, s, \mathrm{COCH}_{3}\right) .{ }^{13} \mathrm{C} \mathrm{NMR}$ (in $\mathrm{CDCl}_{3}, \delta \mathrm{ppm}$ ): $194.2\left(\mathrm{COCH}_{3}\right), 23.8\left(\mathrm{COCH}_{3}\right)$.

\subsection{Material and sample preparation}

Mild steel specimens with chemical composition provided in Table 1 were used in this study as working electrodes, the dimension of each was $(6 \times 6 \times 0.1 \mathrm{~cm})$. They were degreased ultrasonically with a bath of acetone, then washed twice with distilled water, and finally dried with hot air. The electrolyte solution $(1 \mathrm{M} \mathrm{HCl})$ was prepared by using analytical grade $35.4 \% \mathrm{HCl}$ and distilled water. Three concentrations of inhibitors (100, 200 and $300 \mathrm{ppm})$ were added to the $\mathrm{HCl}$ solution, the inhibitors were dissolved in droplets of acetone.

Table 1. Chemical composition in wt. \% for mild steel.

\begin{tabular}{ccccccccc}
\hline $\mathbf{C}$ & $\mathbf{S i}$ & $\mathbf{M n}$ & $\mathbf{N i}$ & $\mathbf{S}$ & $\mathbf{P}$ & $\mathbf{C r}$ & $\mathbf{C u}$ & As \\
\hline $0.08-0.12$ & Max & $0.25-0.50$ & Max & Max & Max & Max & Max & Max \\
Average $\approx 0.10$ & 0.3 & & 0.3 & 0.04 & 0.035 & 0.1 & 0.3 & 0.08 \\
\hline
\end{tabular}

\subsection{Electrochemical measurement}

Electrochemical studies were conducted in a three-electrode cell consisting of counter electrode of graphite, saturated calomel electrode (SCE), and mild steel specimen with exposed area of $4.9 \mathrm{~cm}^{2}$ as working electrode. Polarization and EIS methods were used to examine the corrosion behavior of mild steel in $1 \mathrm{M} \mathrm{HCl}$ at different concentrations of the tested inhibitors at room temperature. These results were compared with the corresponding 
results from corrosion of mild steel in plain $1 \mathrm{M} \mathrm{HCl}$ (no inhibitors). The polarization experiments were carried out using Gamry potentiostat Ref 600 instrument and Gamry framework software. Prior to each potentiodynamic polarization test, the working electrode was immersed in the electrolyte solution for about $30 \mathrm{~min}$ to reach steady state situation, i.e. open circuit potential (OCP). Potentiodynamic polarization tests were carried out by applying an external potential on the mild steel sample, with potential range $(-800$ to $-100 \mathrm{mV})$ with respect to the reference electrode and $0.5 \mathrm{mV} \cdot \mathrm{s}^{-1}$ as scan rate. EIS tests were carried out using a potentiostat (Voltalab, PGZ 100) and VoltaMaster 4 software. The AC impedance was measured for a frequency range of $40 \mathrm{KHz}$ to $10 \mathrm{~Hz}$ with amplitude of $10 \mathrm{mV}$.

\subsection{Quantum chemical study}

Density functional theory is used as a tool that predicts the inhibition performance of the inhibitors according to their structures. The structures of L1-L3 were optimized using density functional theory B3LYP functional, the optimization process was carried out using GAUSSIAN 09 program package and the $6-31 \mathrm{G}^{*}$ basis set for $\mathrm{C}, \mathrm{H}, \mathrm{N}, \mathrm{O}, \mathrm{S}$ and $\mathrm{Cl}$. The distribution of each Molecular Orbital (MO) on different constituents was calculated using the Gauss Sum Program.

\subsection{Scanning electron microscopy study (SEM)}

QUANTA FEG450 SEM instrument was used to examine the surface morphology of mild steel samples before and after corrosion testing, in absence and presence of the inhibitors.

\section{Results and Discussion}

\subsection{Potentiodynamic polarization test}

Potentiodynamic polarization curves of the mild steel in $1 \mathrm{M} \mathrm{HCl}$ at room temperature without any inhibitor and at $200 \mathrm{ppm}$ concentration of L1, L2 and L3 are presented in Figure 2 as an example of the attained curves from polarization experiments. Electrochemical parameters such as corrosion potential $\left(E_{\text {corr }}\right)$, corrosion current density $\left(i_{\text {corr }}\right)$, anodic Tafel slope $\left(B_{\mathrm{a}}\right)$, and cathodic Tafel slope $\left(B_{\mathrm{c}}\right)$ are all listed in Table 2 . The inhibition efficiency $\eta(\%)$ was calculated by the following equation:

$$
\eta(\%)=\frac{i_{\text {corr }}-i_{\text {corr(inh) }}}{i_{\text {corr }}} \cdot 100
$$

Where $i_{\text {corr }}$ and $i_{\text {corr(inh) }}$ are corrosion current densities values in absence and in the presence of the corrosion inhibitors, respectively.

It is evident from Figure 2 and Table 2 that the presence of inhibitors decreases the corrosion current density of mild steel as compared to its value without adding any inhibitors, this suggests that L1, L2 and L3 inhibit the corrosion of mild steel in $1 \mathrm{M} \mathrm{HCl}$ solution. Also, the presence of inhibitors shifts $E_{\text {corr }}$ to less negative values. This indicates that the used 
inhibitors act as anodic-type inhibitors [16]. The almost unaffected cathodic and anodic Tafel slope in the presence of the inhibitors mean that the inhibition takes place by absorption of the inhibitors molecules on the mild steel surface and thus blocking the active sites without changing the cathodic and anodic reaction mechanism $[1,5]$. In addition, the increase of L1 and L2 concentration results in a decrease of the corrosion current density $\left(i_{\text {corr }}\right)$. Hence, the inhibition efficiency increases. The highest corrosion inhibition efficiency achieved was $69 \%$ for L2 at $300 \mathrm{ppm}$. However, opposite behavior was observed for L3 inhibitor, where the inhibition efficiency decreased with increase of concentration. This behavior is attributed to the presence of aggressive chlorine ions in L3. The maximum value of corrosion inhibition efficiency of L3 was 62 obtained at 100 ppm concentration. Figure 3 shows the effect of inhibitor concentration on inhibition efficiency.

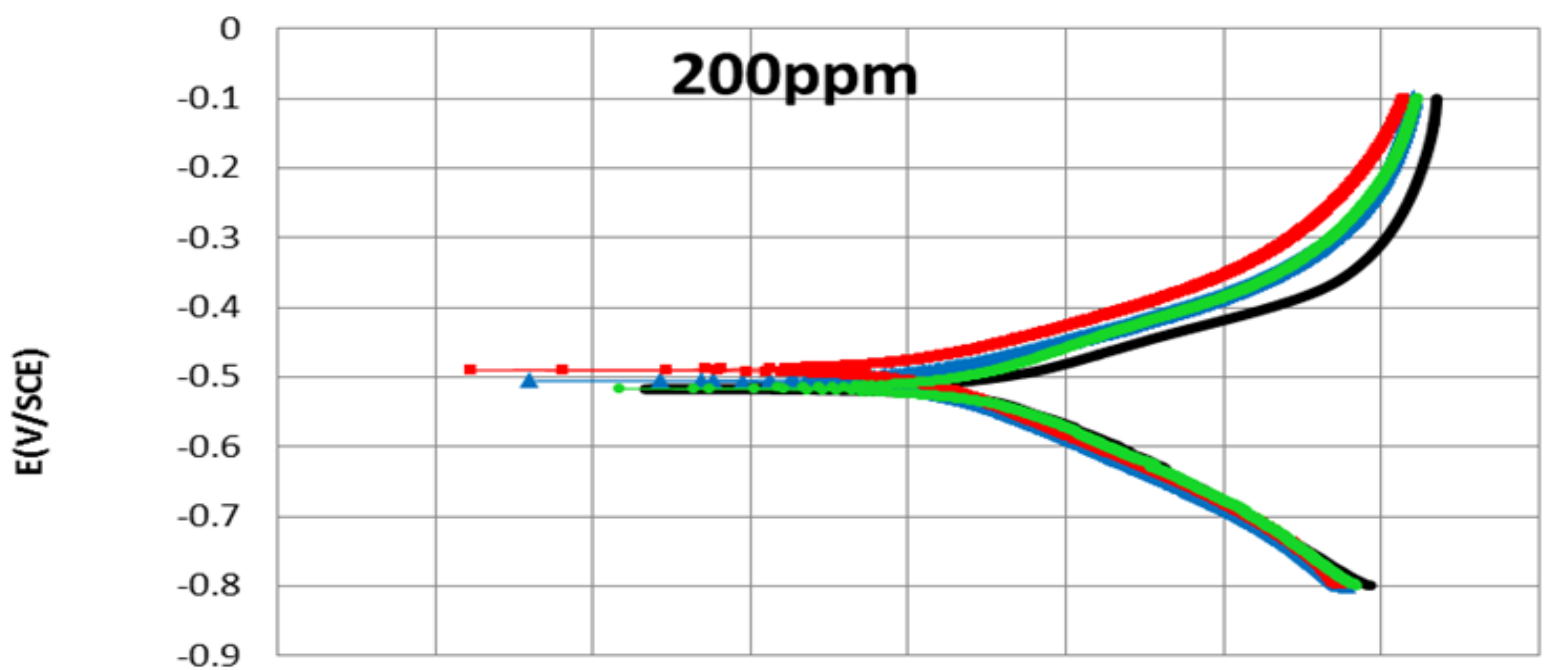

1.00E-08 1.00E-07 1.00E-06 1.00E-05 1.00E-04 1.00E-03 1.00E-02 1.00E-01 1.00E+00 $\log I\left(A / \mathrm{cm}^{\wedge} 2\right)$

$\longrightarrow$ blank $\longleftarrow \mathrm{L} 1 \multimap \mathrm{L} 2 \multimap \mathrm{L} 3$

Figure 2. Potentiodynamic polarization curves for mild steel in $1 \mathrm{M} \mathrm{HCl}$ without any inhibitor and at $200 \mathrm{ppm}$ concentration of L1, L2 and L3 inhibitors at room temperature.

Table 2. Potentiodynamic polarization parameters for mild steel in $1 \mathrm{M} \mathrm{HCl}$ without inhibitors and with various concentrations of L1, L2 and L3 at room temperature.

\begin{tabular}{cccccccc}
\hline Electrolyte Type & $\begin{array}{c}\boldsymbol{C} \\
(\mathbf{p p m})\end{array}$ & $\begin{array}{c}\boldsymbol{B}_{\mathbf{a}} \cdot \mathbf{1 0}^{-\mathbf{2}} \\
(\mathbf{V} / \mathbf{d e c a d e})\end{array}$ & $\begin{array}{c}\boldsymbol{B}_{\mathbf{c}} \cdot \mathbf{1 0}^{-2} \\
(\mathbf{V} / \mathbf{d e c a d e})\end{array}$ & $\begin{array}{c}\boldsymbol{i}_{\text {corr }} \\
(\boldsymbol{\mu} \mathbf{A})\end{array}$ & $\begin{array}{c}-\boldsymbol{E}_{\text {corr }} \\
(\mathbf{m V})\end{array}$ & $\begin{array}{c}\text { Corrosion Rate } \\
(\mathbf{m p y})\end{array}$ & $\boldsymbol{\eta}(\boldsymbol{\%})$ \\
\hline $\begin{array}{c}\text { Plain 1 M HCl } \\
\text { (No inhibitor) }\end{array}$ & - & 7.12 & 11.5 & 358 & 516 & 33.4 & - \\
\hline & 100 & 6.79 & 10.2 & 191 & 509 & 17.9 & 47 \\
$1 \mathrm{M} \mathrm{HCl}+\mathrm{L} 1$ & 200 & 6.58 & 9.74 & 158 & 506 & 14.8 & 56 \\
& 300 & 6.67 & 9.26 & 117 & 497 & 10.97 & 67 \\
\hline
\end{tabular}




\begin{tabular}{cccccccc}
\hline Electrolyte Type & $\begin{array}{c}\boldsymbol{C} \\
(\mathbf{p p m})\end{array}$ & $\begin{array}{c}\boldsymbol{B}_{\mathbf{a} \cdot \mathbf{1 0}^{-\mathbf{2}}} \\
(\mathbf{V} / \mathbf{d e c a d e})\end{array}$ & $\begin{array}{c}\boldsymbol{B}_{\mathbf{c}} \cdot \mathbf{1 0}^{-2} \\
(\mathbf{V} / \mathbf{d e c a d e})\end{array}$ & $\begin{array}{c}\boldsymbol{i}_{\text {corr }} \\
(\boldsymbol{\mu} \mathbf{A})\end{array}$ & $\begin{array}{c}-\boldsymbol{E}_{\text {corr }} \\
(\mathbf{m V})\end{array}$ & $\begin{array}{c}\text { Corrosion Rate } \\
(\mathbf{m p y})\end{array}$ & $\boldsymbol{\eta}(\boldsymbol{\%})$ \\
\hline \multirow{2}{*}{$1 \mathrm{M} \mathrm{HCl+L2}$} & 200 & 7.88 & 9.34 & 156 & 504 & 14.61 & 56 \\
& 300 & 6.50 & 9.68 & 111 & 490 & 10.40 & 69 \\
\hline \multirow{2}{*}{$1 \mathrm{M} \mathrm{HCl+L3}$} & 100 & 6.91 & 8.71 & 128 & 505 & 12.0 & 64 \\
& 200 & 7.54 & 9.73 & 227 & 511 & 21.22 & 37 \\
\hline
\end{tabular}

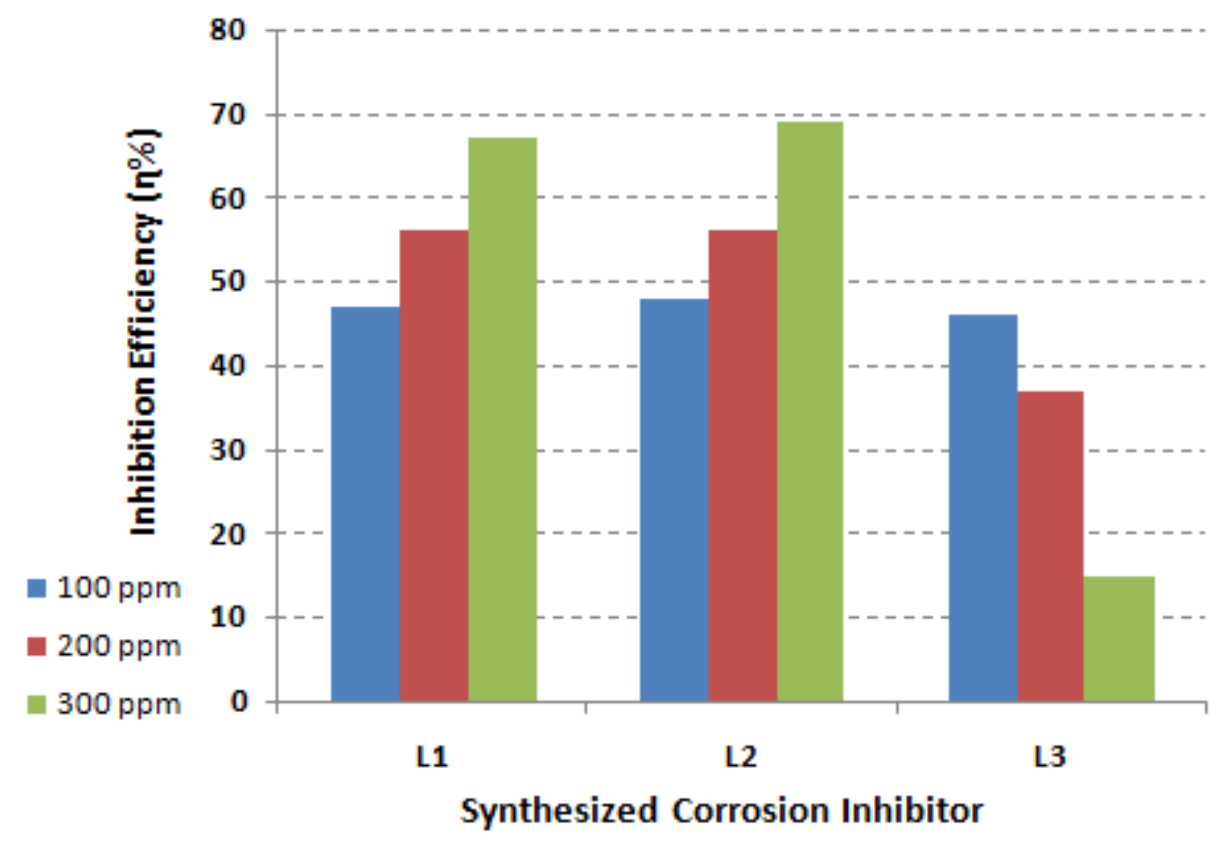

Figure 3. The effect of inhibitor concentration on inhibition efficiency.

\subsection{Impedance spectroscopy measurements (EIS)}

EIS is used to evaluate the inhibition performance of the corrosion inhibitors and get specific information about the inhibition mechanism of mild steel without inhibitors and with different concentrations of tested the inhibitors in $1 \mathrm{M} \mathrm{HCl}$ solution at room temperature.

The electrochemical impedance measurements (Nyquist plots) were obtained for the various concentrations of the inhibitors at the open-circuit potential. The impedance diagrams were then recorded for mild steel in $1 \mathrm{M} \mathrm{HCl}$ and are shown in Figures 4 and 5. The experimental data were fitted using the equivalent circuit shown in Figure 6 from which the circuit parameters were evaluated. 


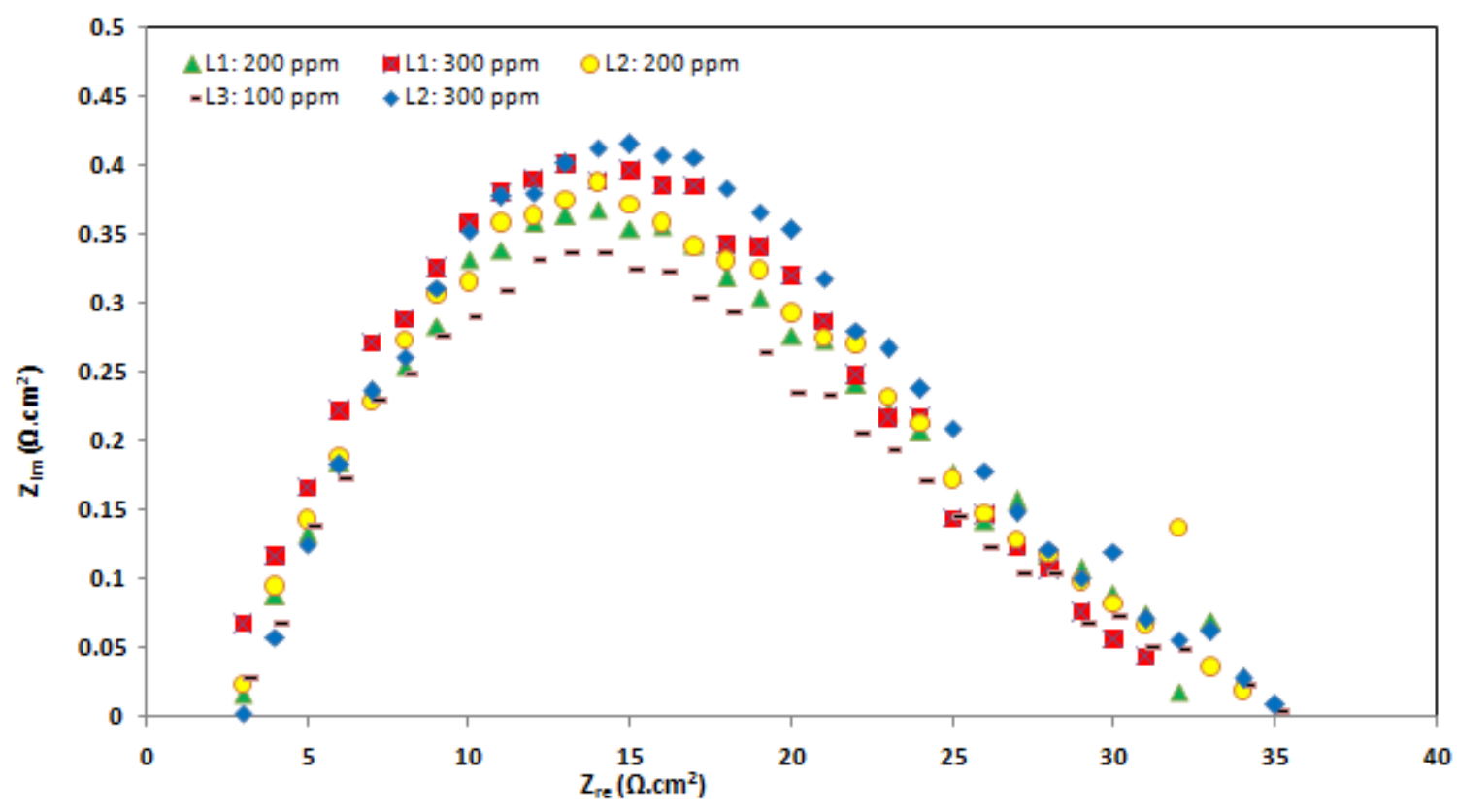

Figure 4. Nyquist plots for mild steel in $1 \mathrm{M} \mathrm{HCl}$ solution with [200 ppm L1; 300 ppm L1; 200 ppm L2; 300 ppm L2, and 100 ppm L3] concentrations at room temperature.

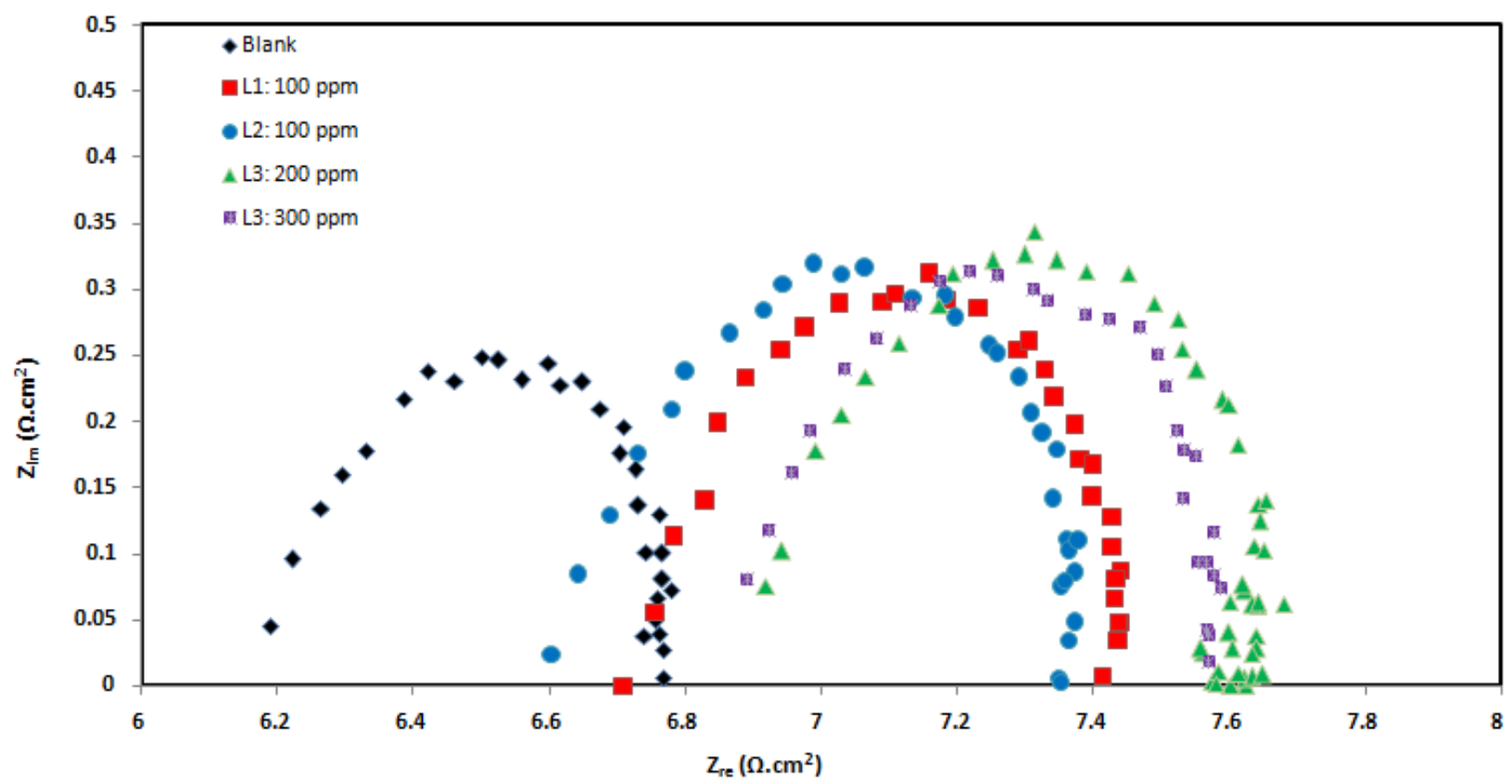

Figure 5. Nyquist plots for mild steel in $1 \mathrm{M} \mathrm{HCl}$ solution with various concentrations of L1, L2 and L3 at room temperature.

The values of electrolyte resistance $R_{\mathrm{S}}$, the charge transfer resistance $R_{\mathrm{CT}}$, the percentage inhibition efficiency (\%IE) was calculated employing the $R_{\mathrm{CT}}$ values by the following equation [1]:

$$
I E(\%)=\frac{R_{\mathrm{CT}}-R_{\mathrm{CT}}^{0}}{R_{\mathrm{CT}}^{0}} \cdot 100
$$


Where $R_{\mathrm{CT}}^{0}$ and $R_{\mathrm{CT}}$ are the charge transfer resistance in the absence and in the presence of the corrosion inhibitors, respectively. The increase of $R_{\mathrm{CT}}$ and the decrease of $C_{\mathrm{DL}}$ values for inhibited systems were observed. The values of the electrochemical parameters: $R_{\mathrm{s}}, C_{\mathrm{DL}}, R_{\mathrm{CT}}$ and the calculated percent inhibition efficiency (IE\%) are listed in Table 3. Generally, we noticed that the values of $R_{\mathrm{CT}}$ and the $I E \%$ increased with increasing the inhibitor concentration. However, the values of $C_{\mathrm{DL}}$ decreased upon increasing the inhibitor concentration. The decreasing trend in $C_{\mathrm{DL}}$ is due to the adsorption of the inhibitor on the surface of mild steel. The impedance curves consist of one single capacitive loop indicating that the corrosion of mild steel is primarily dominated by charge transfer [17]. The shapes of the impedance curves are similar indicating that the corrosion mechanism is similar in all the samples. The diameter of the capacitive loop in the presence of inhibitor are always larger than that in blank solution, and extends as a function of the inhibitor concentration. This indicates that the impedance of inhibited metal is directly proportional to the inhibitor concentration. Also, we noticed that the diameter of the semicircle in the Nyquist plots increases with increasing the concentration of L1 and L2 while it decreases upon the increase in L3 concentration. This means that the inhibition performance of L1 and L2 is increased with increasing their concentration while for L3 it is decreased with increasing its concentration. The largest semicircle diameter was obtained for L2 at $300 \mathrm{ppm}$ concentration, which indicates that it was the best inhibitor in $1 \mathrm{M} \mathrm{HCl}$. The deviation observed of Nyquist plots from ideal semicircle shape (frequency dispersion) may be related to the inhomogeneity and the roughness of mild steel surface [18].

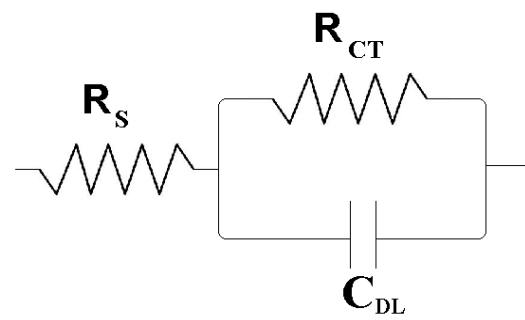

Figure 6. The equivalent circuit used to fit the impedance parameters.

Table 3. EIS parameters and inhibition efficiency for mild steel in $1 \mathrm{M} \mathrm{HCl}$ without and with various concentrations of L1, L2 and L3 at room temperature.

\begin{tabular}{cccccc}
\hline Type & $\begin{array}{c}\boldsymbol{C} \\
(\mathbf{p p m})\end{array}$ & $\begin{array}{c}\boldsymbol{R}_{\mathbf{s}} \\
\left(\mathbf{O h m} \cdot \mathbf{c m}^{2}\right)\end{array}$ & $\begin{array}{c}\boldsymbol{R} \mathbf{C T} \\
\left(\mathbf{O h m} \cdot \mathbf{c m}^{2}\right)\end{array}$ & $\begin{array}{c}\boldsymbol{C} \mathbf{D L} \\
\left(\boldsymbol{\mu} \mathbf{F} / \mathbf{c m}^{2}\right)\end{array}$ & $\boldsymbol{I E \%}$ \\
\hline Blank & - & 7.01 & 0.58 & 123.6 & - \\
\hline \multirow{3}{*}{ 1 M HCl+L1 } & 100 & 6.72 & 0.75 & 84.88 & 46 \\
& 200 & 7.16 & 0.90 & 78.7 & 57 \\
& 300 & 7.33 & 0.98 & 72.81 & 70 \\
\hline
\end{tabular}




\begin{tabular}{cccccc}
\hline Type & $\begin{array}{c}\boldsymbol{C} \\
(\mathbf{p p m})\end{array}$ & $\begin{array}{c}\boldsymbol{R}_{\mathbf{S}} \\
\left(\mathbf{O h m} \cdot \mathbf{c m}^{2}\right)\end{array}$ & $\begin{array}{c}\boldsymbol{R}_{\mathbf{C T}} \\
\left(\mathbf{O h m} \cdot \mathbf{c m}^{2}\right)\end{array}$ & $\begin{array}{c}\boldsymbol{C}_{\mathbf{D L}} \\
\left(\boldsymbol{\mu} \mathbf{F} / \mathbf{c m}^{2}\right)\end{array}$ & $\boldsymbol{I E \%}$ \\
\hline \multirow{3}{*}{$1 \mathrm{M} \mathrm{HCl}+\mathrm{L} 2$} & 100 & 6.45 & 0.75 & 84.4 & 46 \\
& 200 & 7.40 & 0.92 & 77.8 & 59 \\
& 300 & 7.13 & 1.0 & 71.65 & 72 \\
\hline \multirow{3}{*}{ 1 M HCl+L3 } & 100 & 7.64 & 0.93 & 76.5 & 62 \\
& 200 & 6.48 & 0.70 & 90.9 & 36 \\
& 300 & 6.95 & 0.68 & 102.4 & 21 \\
\hline
\end{tabular}

\subsection{Quantum chemistry calculations}

DFT is a good tool to explain the relationship between the structures of the inhibitors and their effect on inhibition efficiency [19]. Several quantum chemical parameters such as the energy of lowest unoccupied molecular orbital $\left(E_{\mathrm{LUMO}}\right)$, the highest occupied molecular orbital $\left(E_{\mathrm{HOMO}}\right)$, energy gap between $E_{\mathrm{HOMO}}$ and $E_{\mathrm{LUMO}}(\Delta E)$, global hardness $(\rho)$, softness $(\sigma)$, electronegativity $(\chi)$, ionization energy $(I)$ and fraction of electrons transferred $(\Delta N)$ have been derived and discussed to understand the interaction between mild steel surface and corrosion inhibitors molecules. The calculated parameters are summarized in Table 4. The optimized structure of the molecule is shown in Figure 7, and the frontier electron distribution of the neutral inhibitors molecules are shown in Figure 8.

$E_{\mathrm{HOMO}}$ associated with electron donating ability of the molecule, the less negative $E_{\mathrm{HOMO}}$ of the inhibitors molecule the higher its tendency to give electrons to the unfilled d-orbital of the surface metal atoms. Further, the $E_{\text {LUMO }}$ indicates the electrons accepting ability of a molecule; the more negative $E_{\mathrm{LUMO}}$, the greater electron accepting ability of the inhibitor molecule. The energy gap $\Delta E\left(\Delta E=E_{\mathrm{LUMO}}-E_{\mathrm{HOMO}}\right)$ is another parameter that associated with chemical reactivity and the inhibition efficiency of molecules, the lower $\Delta E$ the higher chemical reactivity and corrosion inhibition efficiency [4,5], the $\Delta E$ values are decreased in the order of L2 $<\mathrm{L} 1<\mathrm{L} 3$ indicating that L2 has the greatest tendency of adsorption.

Table 4. The quantum chemical parameters for the tested corrosion inhibitors.

\begin{tabular}{cccc}
\hline & \multicolumn{3}{c}{ Inhibitor } \\
\cline { 2 - 4 } Quantum Chemical Parameter & $\mathbf{L 1}$ & $\mathbf{L 2}$ & $\mathbf{L 3}$ \\
\cline { 2 - 4 } & -5.56 & -5.51 & -5.62 \\
$E_{\text {HOMO }}(\mathrm{eV})$ & -1.86 & -1.85 & -1.91 \\
$E_{\mathrm{LUMO}}(\mathrm{eV})$ & 3.70 & 3.66 & 3.71 \\
$\Delta E(\mathrm{eV})$ & 5.56 & 5.51 & 5.62 \\
$I(\mathrm{eV})$ & 1.86 & 1.85 & 1.91 \\
$A(\mathrm{eV})$ & & & \\
\hline
\end{tabular}




\begin{tabular}{cccc}
\hline \multirow{2}{*}{ Quantum Chemical Parameter } & \multicolumn{3}{c}{ Inhibitor } \\
\cline { 2 - 4 } & L1 & L2 & L3 \\
\hline$\chi(\mathrm{eV})$ & 3.71 & 3.68 & 3.77 \\
$\gamma(\mathrm{eV})$ & 1.85 & 1.83 & 1.86 \\
$\sigma(\mathrm{eV})^{-1}$ & 0.541 & 0.546 & 0.539 \\
$\Delta N$ & 0.889 & 0.907 & 0.872 \\
\hline
\end{tabular}

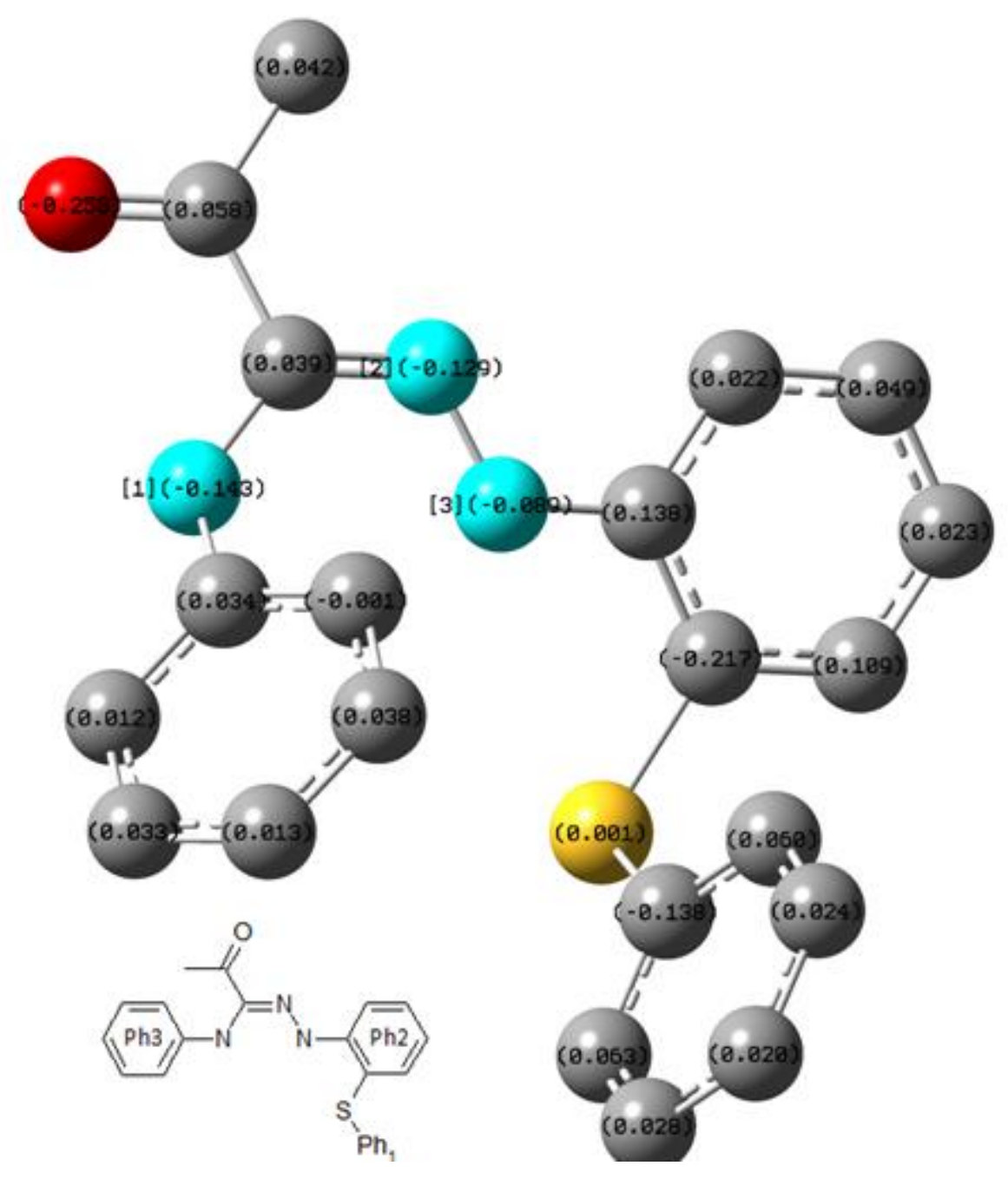

Figure 7. The optimized structure for molecules.

$E_{\mathrm{HOMO}}$ and $E_{\mathrm{LUMO}}$ of the corrosion inhibitor molecules are related to ionization potential $(I)$ and electron affinity $(A)$, respectively $[7,20]$ :

$$
\begin{aligned}
& I=-E_{\text {HOMO }} \\
& A=-E_{\text {LUMO }}
\end{aligned}
$$




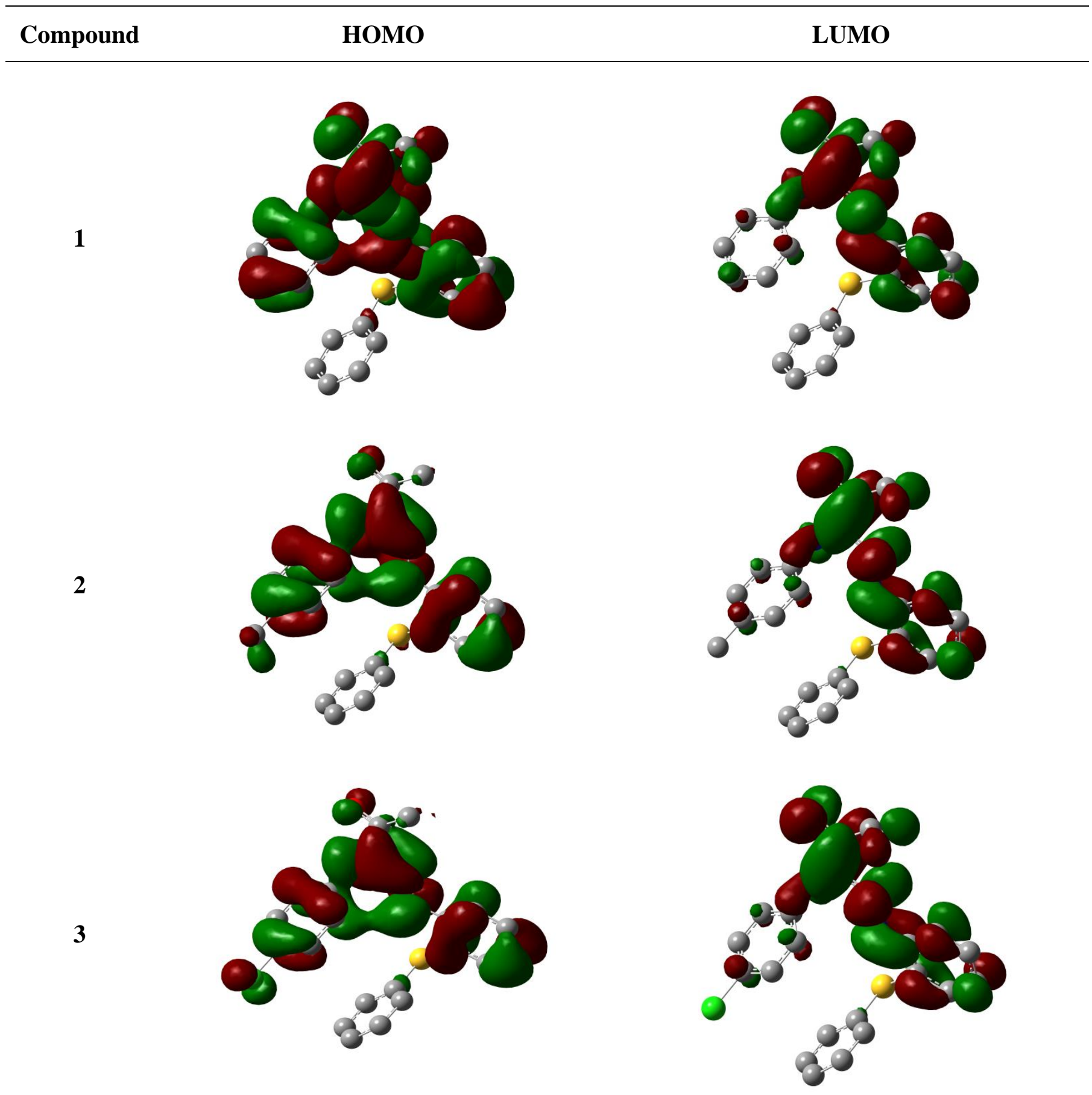

Figure 8. HOMO and LUMO distribution for inhibitors molecules.

Then absolute value of electronegativity $(\chi)$ and global hardness $(\gamma)$ of the inhibitor molecules are calculated as follows [7,20]:

$$
\begin{aligned}
& \chi=\frac{I+A}{2} \\
& \gamma=\frac{I-A}{2}
\end{aligned}
$$


Global hardness $(\gamma)$ and global softness $(\sigma)$ are measuring the stability and reactivity of molecules, the global softness $(\sigma)$ is calculated as follows $[7,20]$ :

$$
\sigma=\frac{1}{\gamma}
$$

A higher value of softness and a lower value of hardness are associated with high chemical reactivity and high inhibition efficiency [4]. Furthermore, the hardness values decrease in the order of $\mathrm{L} 2<\mathrm{L} 1<\mathrm{L} 3$, the softness values increase in the order of $\mathrm{L} 2>\mathrm{L} 1>\mathrm{L} 3$ which in accordance to the order of experimental inhibition efficiency.

The fraction of electrons transferred parameter $(\Delta N)$ as shown in the equation below, is used to explain the transfer of electrons between inhibitors and iron [21].

$$
\Delta N=\frac{\chi_{\mathrm{Fe}}-\chi_{\mathrm{inh}}}{2\left(\gamma_{\mathrm{Fe}}-\gamma_{\mathrm{inh}}\right)}
$$

Where $\chi_{\mathrm{Fe}}$ is the absolute electronegativity of the iron $(\mathrm{Fe}), \chi_{\mathrm{Fe}}=7 \mathrm{eV}$ and $\chi_{\mathrm{inh}}$ represent the absolute electronegativity the inhibitors, $\gamma_{\mathrm{Fe}}$ and $\gamma_{\text {inh }}$ are the absolute hardness of iron atom $(\mathrm{Fe})$ and the inhibitors molecules, the global hardness of $\gamma_{\mathrm{Fe}}=0$. If $\Delta N>0$ the electron transfer from the inhibitor molecule to the surface of metal and opposite action if $\Delta N<0$. And the corrosion inhibition efficiency increases with increasing tendency to donate electrons to the vacant d-orbital of the metal if $\Delta N<3.6$. It is obvious from results in Table 4 for all tested corrosion inhibitors the values of $\Delta N$ are positive indicating electron transferring from the inhibitor molecules to the metal [1,21].

\subsection{Scanning electron microscopic (SEM)}

The surface morphology of mild steel samples in contact with $1 \mathrm{M} \mathrm{HCl}$ solution were studied using SEM in the absence and presence of the corrosion inhibitors before and after corrosion test. Figure 9(a) shows the surface morphology of a mild steel sample before corrosion testing, no pits were observed. However, both marks and residues appeared as traces of polishing process during sample preparation. After corrosion testing; the surface is severely corroded with many pits and cavities of different sizes, due to the corrosive acid attack as shown in Figure 9(b).

Figure 10(a,b) shows the mild steel surface morphology after corrosion testing in the presence of $100 \mathrm{ppm}$ and $300 \mathrm{ppm}$ of L1, respectively. The used inhibitor slowed down the corrosion, fewer cracks and pits observed on the corroded surfaces as compared with these observed in Figure 9(b) (blank $1 \mathrm{M} \mathrm{HCl}$ ). This can be explained by the adsorption of the inhibitors on the mild steel surface, blocking the active sites on mild steel surface thus protecting it from the direct attack of the acidic media. Also, it can be noticed that the surface become smoother with the increase of inhibitor concentration. 


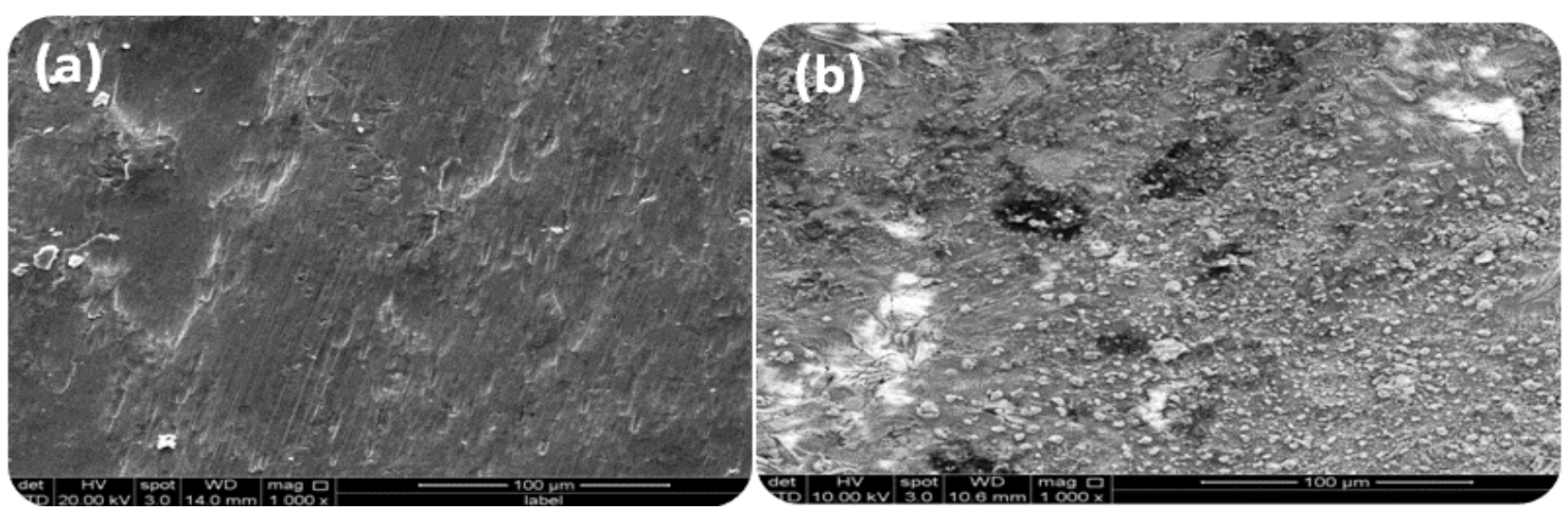

Figure 9. SEM micrographs of mild steel surfaces at $100 \mu \mathrm{m}$ scales: (a) before corrosion test; (b) blank $1 \mathrm{M} \mathrm{HCl}$ after corrosion test.

SEM images show the absence of large pits on the corroded surfaces in the presence of inhibitors (L1, L2, and L3). These results are in agreement with the electrochemical data attained from polarization, EIS experiments and the theoretical results predicted by the quantum chemistry calculations.
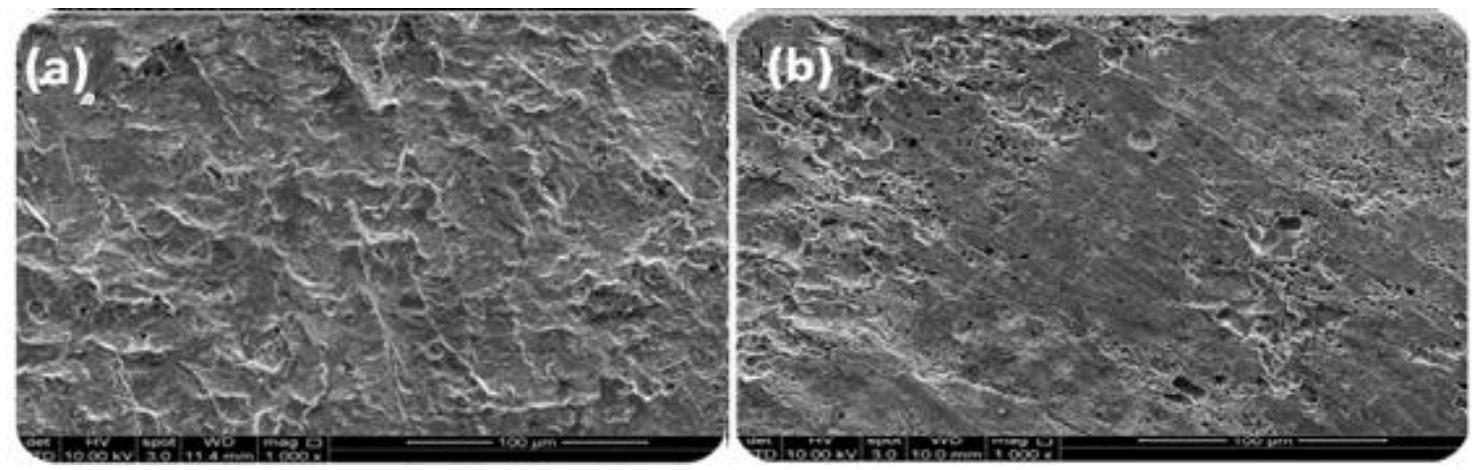

Figure 10. SEM micrographs of mild steel surfaces at $100 \mu \mathrm{m}$ micro scales in the presence of (a) 100 ppm L1, (b) 300 ppm L1.

\section{Conclusions}

The effects of the corrosion inhibitors L1, L2 and L3 on mild steel in $1 \mathrm{M} \mathrm{HCl}$ aqueous solution were investigated using polarization test, electrochemical impedance spectroscopy (EIS), quantum chemical calculations and scanning electron microscopy (SEM). The main conclusions can be obtained from this study are as follows:

1. For the examined concentrations range, the inhibition performance increases with increasing L1 and L2 concentration and decreases with increasing L3 concentration. The maximum corrosion inhibition efficiency of $69 \%$ for L2 at $300 \mathrm{ppm}$ at room temperature.

2 . The potentiodynamic polarization studies suggest that the tested inhibitors act as anodictype inhibitors. 
3. EIS measurement indicates that the adsorption of inhibitors molecules on mild steel surface increased with increasing the charge transfer resistance $\left(R_{\mathrm{CT}}\right)$ and decreasing the double-layer capacitance $\left(C_{\mathrm{DL}}\right)$.

4. The corrosion inhibitor molecules adsorbed on the mild steel surface and blocked the active sites. Thicker protective film has formed by increasing the concentration of L1 and L2. Scanning electron microscopic (SEM) results confirmed that.

5. Quantum chemical study showed a correlation between theoretical calculations and experimental results.

\section{Acknowledgements}

Authors express their gratitude to the Deanship of Scientific Research at Jordan University of Science and Technology (J.U.S.T.) for funding this work via the grant no. 15/2018. E.A. acknowledges the financial support from the Deanship of Scientific Research at the University of Jordan (Projects No. 2007 and 2176).

\section{References}

1. C. Verma, E. Ebenso, Y. Vishal and M.A. Quraishi, Dendrimers: A newclass of corrosion inhibitors for mild steel in $1 \mathrm{M} \mathrm{HCl}$, J. Mol. Liq., 2016, 224, 1282-1293. doi: 10.1016/j.molliq.2016.10.117

2. P. Kumari, P. Shetty and S. Rao, Electrochemical measurements for the corrosion inhibition of mild steel in $1 \mathrm{M}$ hydrochloric acid by using an aromatic hydrazide derivative, Arabian J. Chem., 2017, 10, no. 5, 653-663. doi: 10.1016/j.arabjc.2014.09.005

3. S. Bilgiç, Plant extracts as corrosion inhibitors for mild steel in HCL media-review I, Int. J. Corros. Scale Inhib., 2021, 10, no. 1, 145-175. doi: 10.17675/2305-6894-202110-1-9

4. P. Dohare, K. Ansari, M. Quraishi and I. Obot, Pyranpyrazole derivatives as novel corrosion inhibitors for mild steel useful for industrial pickling process: Experimental and Quantum Chemical study, J. Ind. Eng. Chem., 2017, 52, 197-210. doi: 10.1016/j.jiec.2017.03.044

5. H. Hamani, T. Douadi, M. Al-Noaimi, S. Issaadi, D. Daoud and S. Chafaa, Electrochemical and quantum chemical studies of some azomethine compounds as corrosion inhibitors for mild steel in $1 \mathrm{M}$ hydrochloric acid, Corros. Sci., 2014, 88, 234-245. doi: 10.1016/j.corsci.2014.07.044

6. M. Prabakaran, S. Kim, N. Mugila, V. Hemapriya, K. Parameswari, S. Chitra and I. Chung, Aster koraiensis as nontoxic corrosion inhibitor for mild steel in sulfuric acid, J. Ind. Eng. Chem., 2017, 52, 235-242. doi: 10.1016/j.jiec.2017.03.052

7. A. Fouda, M. Ismail, G. EL-ewady and A. Abousalem, Evaluation of 4-amidinophenyl2,2'-bithiophene and its aza-analogue as novel corrosion inhibitors for CS in acidic media: Experimental and theoretical study, J. Mol. Liq., 2017, 240, 372-388. doi: $\underline{10.1016 / \text { j.molliq.2017.05.089 }}$ 
8. H. Sin, A.A. Rahim, C. Gan, B. Saad, M. Salleh and M. Umeda, Aquilaria subintergra leaves extracts as sustainable mild steel corrosion inhibitors in $\mathrm{HCl}$, Measurement, 2017, 109, 334-345. doi: 10.1016/j.measurement.2017.05.045

9. M. Deyab, K. Eddahaoui, R. Essehli, T. Rhadfi, S. Benmokhtar and G. Mele, Experimental evaluation of new inorganic phosphites as corrosion inhibitors for carbon steel in saline water from oil source wells, Desalination, 2016, 383, 38-45. doi: 10.1016/j.desal.2016.01.019

10. K. Sabet Bokati, C. Dehghanian and S. Yari, Corrosion inhibition of copper, mild steel and galvanically coupled copper-mild steel in artificial sea water in presence of 1H-benzotriazole, sodium molybdate and sodium phosphate, Corros. Sci., 2017, 126, 272-285. doi: $10.1016 /$ j.corsci.2017.07.009

11. L. Zhou, Y. Lv, Y.Hu, J.Zhao, X. Xia and X. Li, Experimental and theoretical investigations of 1,3,5-tris(4-aminophenoxy)benzene as an effective corrosion inhibitor for mild steel in $1 \mathrm{M} \mathrm{HCl}, \quad J$. Mol. Liq., 2018, 249, 179-187. doi: 10.1016/j.molliq.2017.10.129

12. H. Habeeb, H. Luaib, R. Dakhil, A. Kadhum, A. Al-Amiery and T. Gaaz, Development of new corrosion inhibitor tested on mild steel supported by electrochemical study, Results Phys., 2018, 8, 1260-1267. doi: 10.1016/j.rinp.2018.02.015

13. T. Douadi, H. Hamani, D. Daoud, M. Al-Noaimi and S. Chafaa, Effect of temperature and hydrodynamic conditions on corrosion inhibition of an azomethine compounds for mild steel in $1 \mathrm{M} \mathrm{HCl}$ solution, J. Taiwan Inst. Chem. Eng., 2017, 71, 388-404. doi: 10.1016/j.jtice.2016.11.026

14. H. Hamani, T. Douadi, D. Daoud, M. Al-Noaimi, R. Rikkouh and S. Chafaa, 1-(4-Nitrophenylo-imino)-1-(phenylhydrazono)-propan-2-one as corrosion inhibitor for mild steel in $1 \mathrm{M} \mathrm{HCl}$ solution: Weight loss, electrochemical, thermodynamic and quantum chemical studies, J. Electroanal. Chem., 2017, 801, 425-438. doi: 10.1016/j.jelechem.2017.08.031

15. M. Al-Noaimi, F. Awwadi, A. Hammoudeh and M. Tanash, Mixed thioalkyl-azoimine $\left(\mathrm{SNN}^{\prime}\right) / \alpha$-diimine-ruthenium complexes: synthesis, characterization, DFT calculations, crystal structure and application as pre-catalysts for hydrogenation of acetophenone, Transition Met. Chem., 2019, 44, 355-367. doi: 10.1007/s11243-018-00302-2

16. E. Alibakhshi, M. Ramezanzadeh, G. Bahlakeh, B. Ramezanzadeh, M. Mahdavian and M. Motamed, Glycyrrhiza glabra leaves extract as a green corrosion inhibitor for mild steel in $1 \mathrm{M}$ hydrochloric acid solution: Experimental, molecular dynamics, Monte Carlo and quantum mechanics study, J. Mol. Liq., 2018, 255, 185-198. doi: 10.1016/j.molliq.2018.01.144

17. E. Al Shamaileh, M. Kailani, S. Arar and A. Al-Rawajfeh, Corrosion Inhibition of Aluminium by Cyclohexylamine Dithiocarbamate in Acidic Solution, Stud. Univ. BabesBolyai, Chem., 2014, 59, no. 3, 61-69. 
18. X. Luo, X. Pan, S. Yua, S. Du, C. Zhanga and Y. Liu, Corrosion inhibition of mild steel in simulated seawater solution by a green eco-friendly mixture of glucomannan (GL) and bisquaternary ammonium salt (BQAS), Corros. Sci., 2017, 125, 139-151. doi: 10.1016/j.corsci.2017.06.013

19. L. Jiang, Y. Qiang, Z. Lei, J. Wang, Z. Qin and B. Xiang, Excellent corrosion inhibition performance of novel quinoline derivatives on mild steel in $\mathrm{HCl}$ media: Experimental and computational investigations, J. Mol. Liq., 2018, 255, 53-63. doi: 10.1016/j.molliq.2018.01.133

20. K. Zhang, W. Yang, X. Yin, Y. Chen, Y. Liu, J. Le and B. Xu, Amino acids modified konjac glucomannan as green corrosion inhibitors fo rmild steel in $\mathrm{HCl}$ solution, Carbohydr. Polym., 2018, 181, 191-199. doi: 10.1016/j.carbpol.2017.10.069

21. K.M. Shainy, P.R. Ammal and A. Joseph, Development of passive film and enhancement of corrosion protection of mild steel in hydrochloric acid through the synergistic interaction of 2-amino-4-methyl benzothiazole (AMBT) and (E)-2-methylbenzo[d]thiazol-2-yl) imino-4-methyl) phenol (MBTP), Egypt. J. Pet., 2018, 27, no. 4, 621-632. doi: 10.1016/j.ejpe.2017.09.004 